\title{
Molecular characterization of chickpea (Cicer arietinum L.) genotypes using sequence tagged microsatellite site (STMS) markers
}

\author{
Achala Bakshi ${ }^{1}$, Vinay Kumar ${ }^{2}$, Sushma $\operatorname{Sagar}^{1} \operatorname{Sorabh}$ Chaudhary $^{1}$, Rajendra Kumar $^{1}$ \\ and Mukesh Kumar ${ }^{1^{*}}$
}

${ }^{1}$ Department of Agriculture Biotechnology, Sardar Vallabhbhai Patel University of Agriculture \& Technology, Meerut- 250110 (Uttar Pradesh), INDIA

${ }^{2}$ National Institute of Biotic Stress Management, Raipur- 492001 (Chhattisgarh), INDIA

*Corresponding author. E-mail: mukeshbt05@gmail.com

Received: September 29, 2015; Revised received: March 22. 2016; Accepted: June 7, 2016

\begin{abstract}
Chickpea (Cicer arietinum L.) commonly also known as gram, Chana, Bengal gram and Garbanzo beans is the second most important pulse crop of the world mainly grown in arid and semi-arid regions. Assessment of genetic variability in the base population is the first step in any breeding programme for selection of genetically divergent parents and their use in the crop improvement programme. In the present investigation 20 genotypes of chickpea were characterized using a specific set of 15 numbers of Sequence tagged microsatellite site (STMS) markers. The number of alleles, allelic distribution and their frequency was estimated and found that the 36 alleles amplified with 15 STMS loci having an average of 2.4 alleles per locus. The number of alleles amplified varied from 1 to 4 . The Polymorphic information content value ranged from 0 to 0.965 with an average of 0.373 indicated the considerable efficiency of markers for studying the polymorphism level. All primer showed higher polymorphism among the genotypes except two primers namely, TAA59 and GA105 which were monomorphic in nature. Genetic similarity based on UPGMA clustering the dendrogram grouped the 20 genotypes in three clusters, cluster I, II, III comprised of 2, 4, 14 genotypes, respectively. The maximum similarity was found between genotypes ICRISAT-4183 and ICRISAT7722 (0.972). The present study provided an insight of the inter-relationship among the genotypes and highlights the genetic distance by STMS markers. The genetic diversity revealed in this study could be exploited for selective breeding programme of chickpea improvement.
\end{abstract}

Keywords: Chickpea, Cicer aeritenum, Molecular diversity, Sequence tagged microsatellite markers

\section{INTRODUCTION}

Chickpea (Cicer arietinum L.) commonly also known as gram, Chana, Bengal gram and Garbanzo beans is the second most important food legume after soybean, widely cultivated in tropical, sub-tropical and temperate regions of the world, as a source of protein (Gaur $e t$ $a l ., 2012$ ). It is self-pollinated crop belongs to the family Fabaceae (Kupitcha, 1977) with basic chromosome number $(2 n=2 x=16)$ having a genome size of about $738 \mathrm{Mb}$ (Varshney and Tuberosa, 2013). Chickpea seeds are low in fat and rich source of protein, starch, fiber, minerals, and vitamins, which make it one of the best nutritionally balanced pulses for human consumption (Jukanti et al., 2012) and helps in the reducing blood cholesterol (Poncet et al., 2006). Great importance has been attributed to chickpea in agriculture in view of its higher consumption as human food and livestock fodder (Doddamani et al., 2014) This crop is reported as drought-tolerant, cool-season legume have two distinct known forms of cultivated chickpeas are desi (small seeds, angular ram's head shape, and colored seeds with high percentage of fiber) and kabuli (large seeds, irregular rounded, owl's-head shape, and beige colored seeds with a low percentage of fiber) type (Agarwal et al., 2012).

Knowledge of genetic diversity and relationship within and between the cultivated chickpea genotypes and its wild relatives are of paramount importance and may ensure the long-term success of chickpea improvement programs. DNA based molecular markers have been successfully employed in quantification of genetic diversity, genotype identification, delineation and marker assisted selection (Collard et al., 2005). These have been effectively utilized for the assessment of genetic diversity as compared to the morphological or biochemical markers due to their abundance, high level of polymorphism, reproducibility and being independent of the environment. Molecular markers namely RFLP, RAPD, ISSR and SSRs are mostly used, among these microsatellite or SSRs has become the marker of choice for many applications due to their abundance, high level of repeats number, polymorphisms, manifested as the occurrence of the large number of alleles per locus, and co-dominant inheritance has facilitated their extensive use in genome mapping, phylogenetic 
inference and population genetics. Micro satellite technique employing sequence information of repeat flanking regions to design locus specific PCR primer pairs called "sequenced tagged micro satellite site" (STMS). They are co dominant in nature, highly abundant, and often found polymorphic within populations. Chickpea specific STMS markers have been developed by Huttel et al. (1999) and revealed polymorphism up to desirable extent in chickpea accessions. Genetic analysis using STMS markers in few chickpea genotypes and released varieties of chickpea, desi and kabuli were reported by Singh et al.,2008; Bharadwaj et al., 2010; Rizvi et al., 2014). The STMS markers show high degree of conservation could easily be transferred in to another species. The integration of genomic technologies in chickpea breeding will greatly improve the efficiency of breeding programs in the development of better cultivars and reduce the time required for cultivar development.

Thus, the present investigation was conducted to characterize the 20 elite genotypes /line of chickpea collected from different locations of India using the STMS markers covering the different linkage group.

\section{MATERIALS AND METHODS}

Plant materials: Twenty elite genotypes/accession of Cicer arietinum representing different geographic diversity were collected from different institutes viz. ICRISAT, Hyderabad, IIPR, Kanpur and IARI, New Delhi (Table 1). A set of 15 highly polymorphic STMS markers covering different genomic locations were selected for this study and the sequence information of STMS primers were obtained from earlier reports (Huttel et al., 1999; Winter et al., 1999; and Sethy et al., 2005) (Table 2). The genomic locations for most of the markers were derived from the chickpea genome map (Winter et al., 1999).

Genomic DNA extraction STMS amplification: Total Genomic DNA of individual genotypes of Cicer arietinum was isolated from fresh young leaves using the CTAB method described by Doyle and Doyle (1987) with minor modifications. The modifications included twice extraction with the chloroform: isoamyl alcohol $(24: 1 \mathrm{v} / \mathrm{v})$ and precipitation of DNA by addition of the $2 / 3$ volume of ice-cold isopropanol and incubation of tubes at $-20{ }^{\circ} \mathrm{C}$ for 1 hour. The concentration and quality of each DNA samples were analyzed with Bio photometer (Eppendorf, Germany) followed by running on $0.8 \%$ agarose gel electrophoresis along with $\lambda$ Eco RI / Hind III double digest marker. The DNA was made to a dilution of $25 \mathrm{ng} / \mu \mathrm{l}$ was used for further analysis.

The polymerase chain reactions of 15 STMS primers were carried out using Thermal cycler (Ependorf, Germany). The PCR reaction was performed in volume of $20 \mu \mathrm{l}$ reaction mixture consisting of $1 \mathrm{X}$ PCR assay buffer $(10 \mathrm{mM}$ Tris $\mathrm{HCl}, 1.5 \mathrm{mM} \mathrm{MgCl}$, and $50 \mathrm{mM}$ $\mathrm{KCl}$ ), $250 \mu \mathrm{M}$ dNTPs mix, $0.25 \mathrm{mM}$ of each STMS primer (forward and reverse), 1 Unit of Taq DNA Polymerase (Bangalore Genei, India ) and $50 \mathrm{ng}$ of template genomic DNA. The PCR reaction condition included the initial denaturation at $95{ }^{\circ} \mathrm{C}$ for $2 \mathrm{~min}$ followed by 35 cycles of denaturation at $95{ }^{\circ} \mathrm{C}$ for $20 \mathrm{sec}$, primer annealing at $55^{\circ}-61^{\circ} \mathrm{C}$ for $50 \mathrm{sec}$, and amplification at $72{ }^{\circ} \mathrm{C}$ for $50 \mathrm{sec}$ and a final extension of $72{ }^{\circ} \mathrm{C}$ for $7 \mathrm{~min}$. The PCR products were resolved by electrophoresis on $3.0 \%$ Metaphor agarose system using $1 \mathrm{x}$ TBE buffer and gel image was documented using gel documentation system Alpha imager (Alpha Innotech, USA).

Molecular data analysis: To estimate genetic similarity/dissimilarities between different genotypes the data of banding pattern was used as input. Presence and absence of each amplified band was scored as 1 and 0 , respectively. The binary data matrix was used to genetic relationship using UPGMA clustering algorithm program, NTSYS-pc (Rohlf, 1989). The genetic similarities among the genotypes were performed using Jaccard's similarity coefficient (Jaccard, 1908). The dendrogram was constructed based on Jaccard similarity coefficient following un-weighted pair group method analysis (UPGMA) (Gawel and Jarret, 1991) with the SAHN module of NTSYS-pc to show a phenetic representation of genetic relationships as revealed by the similarity coefficient (Sneath and Sokal, 1973) For each STMS marker, Polymorphism Information Content (PIC) was determined as described by Senior et al. (1998), PIC is a measure of allele diversity at a locus and is equal to $1-\sum\left(\mathrm{P}^{2} \mathrm{ij}\right)$, where $\mathrm{Pij}$ is the frequency of $\mathrm{J}^{\text {th }}$ allele for $\mathrm{i}^{\text {th }}$ locus summed across all allele in the locus. PIC is synonymous with the term "gene diversity" as described by Weir (1996). The PIC value ranging from ' 0 ' (Monomorphic) to ' 1 ' (highly discriminative with many alleles in equal frequency ) is an indication of discriminitative power of marker, not only for number of alleles at a locus but also for relative frequencies of those allele in the genotypes under study.

\section{RESULTS AND DISCUSSION}

Molecular marker analysis: The DNA was extracted form 20 genotypes of chickpea and checked for quality and quantity. The spectrophotometer revealed the 260/280 ratio of about 1.7-1.9 which indicated the presence of good quality of genomic DNA. The electrophoretic separation of genomic DNA on $0.8 \%$ agarose gel revealed the presence of single intact band.

A total of 20 chickpea elite genotypes were characterized using 15 numbers of STMS loci, covering various bin locations on different linkage groups (Table 2). Almost all the STMS primers produced polymorphic pattern except two primers namely, TAA59 and GA105. A total of 36 alleles were found for the 15 STMS loci with an average of 2.4 per locus (Table 3 ). An excellent polymorphism was revealed by STMS markers used for amplification namely GA108 and GA 
Table 1. List of the elite genotypes/accessions of chickpea used for the study.

\begin{tabular}{llll}
\hline S. N. & Name of the genotype/accessions & S.N. & Name of the genotype/accessions \\
\hline 1. & F5-55 & 11. & F5-122 \\
2. & F5-936 & 12. & F5-132 \\
3. & ICRISAT-4151 & 13. & F5-168 \\
4. & ICRISAT-4183 & 14. & ICRISAT-3668 \\
5. & ICRISAT-7722 & 15. & MPJK-4 \\
6. & ICRISAT-7306 & 16. & F5-119 \\
7. & BGD-70 & 17. & F5-164 \\
8. & ICCV-5 & 18. & F5-170 \\
9. & ICRISAT-3673 & 19. & PUSA-1053 \\
10. & F5-109 & 20. & Avarodhi \\
\hline
\end{tabular}

Table 2. List of Sequence tagged microsatellite site (STMS) primers and their sequences used to amplify Chickpea genotypes.

\begin{tabular}{|c|c|c|}
\hline S. $\mathbf{N}$. & STMS Primers & Sequence of the STMS primers \\
\hline 1. & TAA59 & $\begin{array}{l}\text { F- GCAGGAAAGACTCCAGCAATGGATTAA } \\
\text { R- GTTTTGCTCATC }\end{array}$ \\
\hline 2. & TA39 & $\begin{array}{l}\text { F-TTAGCGTGGCTAACTTTATTTGC } \\
\text { R-ATAAATATCCAATTCTGGTAGTTGACG }\end{array}$ \\
\hline 3. & TA194 & $\begin{array}{l}\text { F-TTTTTGGCTTATTAGACTGACTT } \\
\text { R-TTGCCATAAAATACAAAATCC }\end{array}$ \\
\hline 4. & CrtSSR46 & $\begin{array}{l}\text { F-ATGATAGTGGGGGAAGACCT } \\
\text { R-GTGGCAGAGGAACTGATAGA }\end{array}$ \\
\hline 5. & CrtSSR31 & $\begin{array}{l}\text { F-AGCGGCTAAGGTAAGAAGAG } \\
\text { R-AGATAATCAGAGAGATATTTTCACAA }\end{array}$ \\
\hline 6. & CrtSSR47 & $\begin{array}{l}\text { F-TGAGGCCTAAGAGTACCAAA } \\
\text { R-TCTCATCAGGAACAACA }\end{array}$ \\
\hline 7. & CrtSSR75 & $\begin{array}{l}\text { F-GTTTCATTTGCCTTTATTGC } \\
\text { R-ACACGTTAATGTTGTGACGA }\end{array}$ \\
\hline 8. & T54II & $\begin{array}{l}\text { F-GCGCTTTGCCGATAGATACAAAGGG } \\
\text { R-AACAAAAGCTGGAG }\end{array}$ \\
\hline 9. & GA4 & $\begin{array}{l}\text { F-TTGCGTGTCAATCTCATTGG } \\
\text { R-AAACGACAGAGAGTGGCGAT }\end{array}$ \\
\hline 10. & GA16 & $\begin{array}{l}\text { F-CACCTCGTACCATGGTTTCTG } \\
\text { R-TAAATTTCATCCTCTCCGGC }\end{array}$ \\
\hline 11. & GA17 & $\begin{array}{l}\text { F-TAGTCCGTTGTCATCCTCCC } \\
\text { R-CGTTGTGGCCAGAGAGAGA }\end{array}$ \\
\hline 12. & GA24 & $\begin{array}{l}\text { F-TTGCCAAAACCAATAACTCTG } \\
\text { R-TCCCTTTTACACAAGGCCAG }\end{array}$ \\
\hline 13. & GA105 & $\begin{array}{l}\text { F-TGAGGAAACACAAAACGACG } \\
\text { R-ATGCCAGGATTAACAGCACC }\end{array}$ \\
\hline 14. & GA108 & $\begin{array}{l}\text { F-GTTTGTGATGGAGGAAGCGT } \\
\text { R-GCCGCATAGCATTGGTAAGT }\end{array}$ \\
\hline 15 . & TR45 & $\begin{array}{l}\text { F-CCCATACCTTTATTATTTGGCAAC } \\
\text { R-AGTGGAACCCACCAATTTTACTA }\end{array}$ \\
\hline
\end{tabular}

16(Figs. 1 and 2). The highest number of alleles (four alleles) were amplified using the markers namely, GA17, GA108 and T54 II followed by CrtSSR47, GA4, GA16 and GA24 amplified (three alleles), and TA194, TA39, TR45 and CrtSSR46 (two alleles). However, only single allele was amplified with markers namely, TAA59 and CrtSSR75. The maximum numbers of null alleles were observed in T54II and GA17. The distribution analysis of STMS alleles across the genotypes under study revealed that most of the amplified alleles were shared by $C$. arietinum accessions. The numbers of average allele amplified are in agreement with Rizvi et al. (2014) and bit lesser than reported by Singh et al. (2008), who found an average of 3.35 allele per loci were amplified among the different chickpea genotypes. However, Bouhadida et al. (2015) reported as an average value of 7.25 al- leles per locus, using STMS markers, which explain a high level of polymorphism within the cultivars.

Based on the allele frequencies, PIC (Polymorphic Information Content) values for different STMS loci were estimated and found that value ranged from 0 to 0.965 with an average of 0.373 . The marker namely, GA-16 showed maximum PIC value $(0.965)$ because of well distributed three alleles among the genotype of C. arietinum, whereas lower PIC value represented by the marker CrtSSR75 (0.18) and the value (0) represented by the two genotypes namely, TAA59 and GA105 which were monomorphic. Out of fifteen markers used for the study eight showed PIC value higher value than average value. The PIC value found in this study higher than the Rizvi et al. (2014) reported that the PIC value of STMS markers ranged from 0.15 to 0.69 . The higher PIC value reported in the 
Table 3. Detail of STMS loci amplified across the chickpea genotypes/ varieties, allele number, allele frequencies and distribution of allele in various genotypes.

\begin{tabular}{|c|c|c|c|c|c|c|}
\hline S. N. & $\begin{array}{l}\text { STMS Prim- } \\
\text { ers }\end{array}$ & Alleles & $\begin{array}{l}\begin{array}{l}\text { No. of Genotypes } \\
\text { sharing alleles }\end{array} \\
\end{array}$ & $\begin{array}{l}\text { Frequency of } \\
\text { STMS alleles }\end{array}$ & $\begin{array}{l}\text { No. of Genotype } \\
\text { showing amplification }\end{array}$ & PIC \\
\hline 1 & TAA59 & $\mathrm{a}_{1}$ & 1 & 1 & 20 & 0 \\
\hline \multirow[t]{2}{*}{2} & TA39 & $a_{1}$ & 18 & 0.45 & 20 & 0.495 \\
\hline & & $\mathrm{a}_{2}$ & 20 & 0.55 & & \\
\hline \multirow[t]{2}{*}{3} & TA194 & $a_{1}$ & 8 & 0.421 & 19 & 0.496 \\
\hline & & $\mathrm{a}_{2}$ & 11 & 0.578 & & \\
\hline \multirow[t]{2}{*}{4} & CRTSSR46 & $a_{1}$ & 2 & 0.1 & 20 & 0.18 \\
\hline & & $\mathrm{a}_{2}$ & 18 & 0.9 & & \\
\hline 5 & CRTSSR31 & $a_{1}$ & 17 & 1 & 17 & 0 \\
\hline \multirow[t]{3}{*}{6} & CRTSSR47 & $\mathrm{a}_{1}$ & 2 & 0.105 & 20 & 0.566 \\
\hline & & $\mathrm{a}_{2}$ & 11 & 0.553 & & \\
\hline & & $\mathrm{a}_{3}$ & 7 & 0.342 & & \\
\hline 7 & CRTSSR75 & $a_{1}$ & 19 & 1 & 19 & 0 \\
\hline \multirow[t]{4}{*}{8} & T54II & $a_{1}$ & 1 & 0.056 & 20 & 0.512 \\
\hline & & $a_{2}$ & 2 & 0.111 & & \\
\hline & & $\mathrm{a}_{3}$ & 12 & 0.667 & & \\
\hline & & $\mathrm{a}_{4}$ & 3 & 0.167 & & \\
\hline \multirow[t]{3}{*}{9} & GA4 & $a_{1}$ & 14 & 0.228 & 19 & 0.662 \\
\hline & & $\mathrm{a}_{2}$ & 18 & 0.351 & & \\
\hline & & $\mathrm{a}_{3}$ & 19 & 0.404 & & \\
\hline \multirow[t]{3}{*}{10} & GA16 & $a_{1}$ & 13 & 0.074 & 18 & 0.965 \\
\hline & & $\mathrm{a}_{2}$ & 17 & 0.111 & & \\
\hline & & $\mathrm{a}_{3}$ & 18 & 0.129 & & \\
\hline \multirow[t]{4}{*}{11} & GA17 & $\mathrm{a}_{1}$ & 4 & 0.8 & 15 & 0.178 \\
\hline & & $\mathrm{a}_{2}$ & 3 & 0.2 & & \\
\hline & & $\mathrm{a}_{3}$ & 4 & 0.267 & & \\
\hline & & $\mathrm{a}_{4}$ & 4 & 0.267 & & \\
\hline \multirow[t]{3}{*}{12} & GA24 & $a_{1}$ & 3 & 0.125 & 20 & 0.361 \\
\hline & & $\mathrm{a}_{2}$ & 15 & 0.775 & & \\
\hline & & $\mathrm{a}_{3}$ & 3 & 0.15 & & \\
\hline 13 & GA105 & $a_{1}$ & 20 & 1 & 20 & 0 \\
\hline \multirow[t]{4}{*}{14} & GA108 & $a_{1}$ & 3 & 0.026 & 19 & 0.685 \\
\hline & & $\mathrm{a}_{2}$ & 15 & 0.25 & & \\
\hline & & $\mathrm{a}_{3}$ & 19 & 0.355 & & \\
\hline & & $\mathrm{a}_{4}$ & 19 & 0.355 & & \\
\hline \multirow[t]{2}{*}{15} & TR45 & $\mathrm{a}_{1}$ & 18 & 0.475 & 20 & 0.499 \\
\hline & & $\mathrm{a}_{2}$ & 19 & 0.525 & & \\
\hline
\end{tabular}

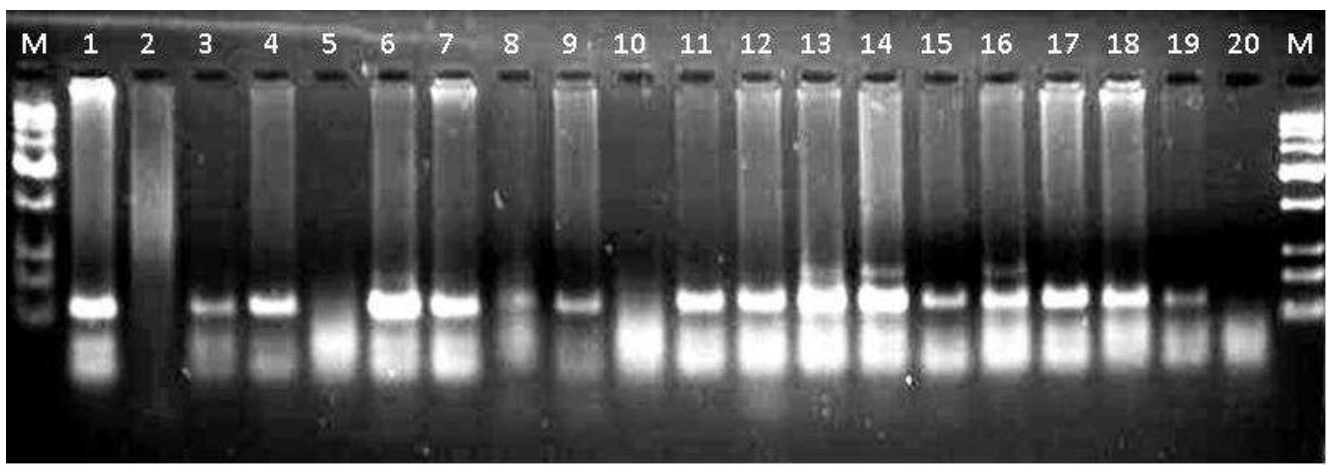

Fig. 1. Molecular profile generated by STMS marker GA108 for 20 chickpea genotypes (Lane 1-20; genotypes as mentioned in Table 1) $M$ - Low range DNA ruler.

study may be due to genotypes have better genetic diversity.

Genetic diversity analysis: The Jaccard's similarity matrix dendrogram constructed using the UPGMA method showed the genetic similarity between genotypes/ lines ranged from 0.47 to 0.97 . The twenty 20 genotypes grouped into 3 major clusters I, II and III comprised of 2, 4, 14 genotypes, respectively (Fig. 3). Cluster I comprised of two genotypes namely, F5-55 and F5-936. Cluster II consisted of four lines, ICRISAT-4151, ICRISAT-4183, ICRISAT-7722 and ICRISAT-7306. All the ICRISAT line grouped in single cluster, showed higher genetic similarity grouped in single cluster except ICRISAT-3673 and 3668. The 


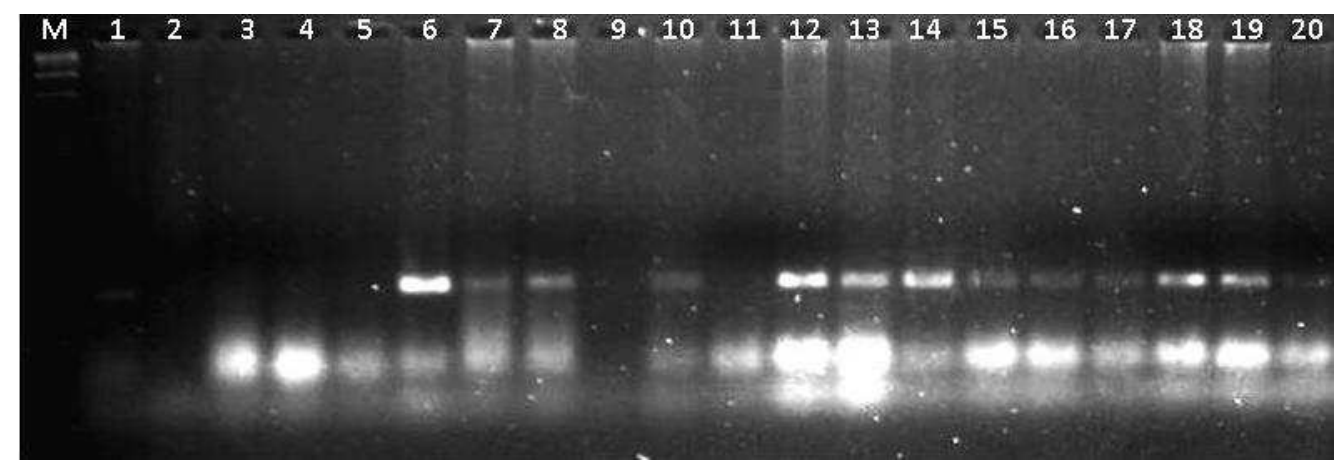

Fig. 2. Molecular profile generated by STMS marker GA16 for 20 chickpea genotypes (Lane 1-20; genotypes as mentioned in Table 1) M: EcoRI / Hind III double digest marker.

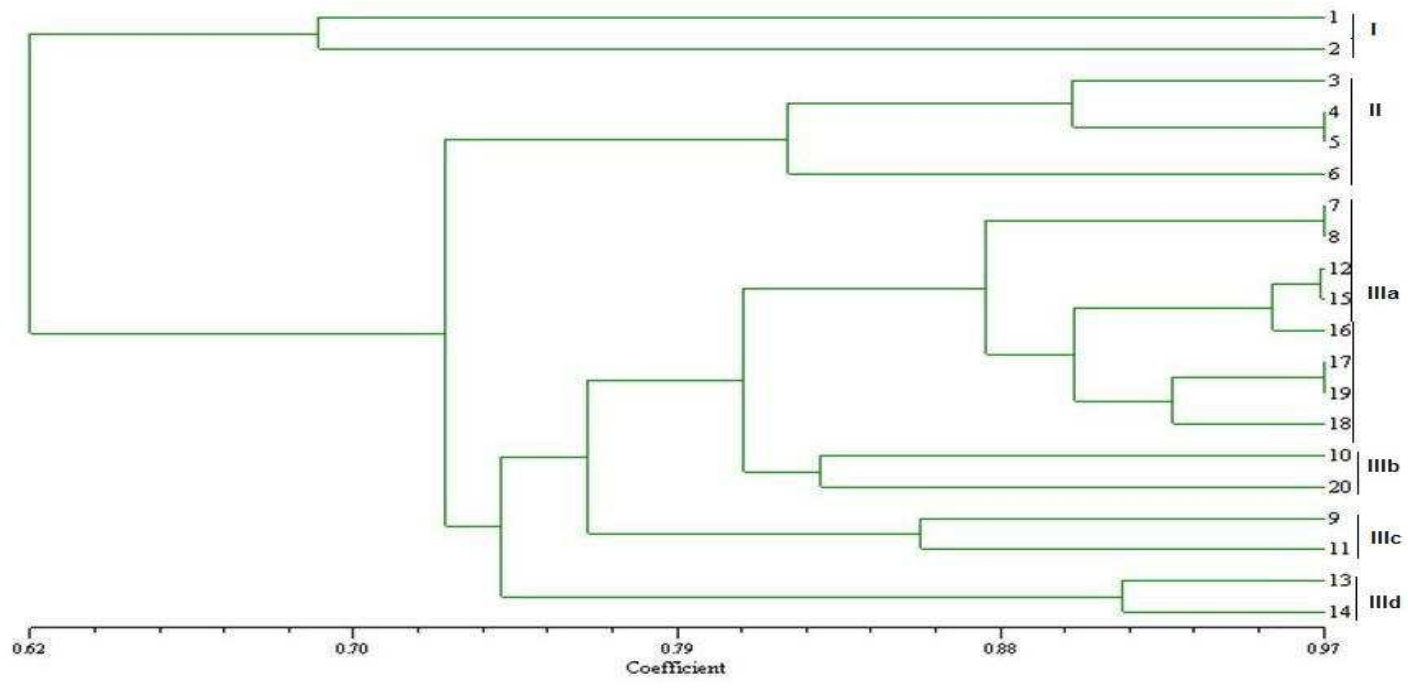

Fig. 3. Dendrogram of 20 genotypes of chickpea generated by UPGMA cluster analysis of genetic similarity based on STMS data. A number detail includes 1. F5-55; 2. F5-936; 3. ICRISAT-4151; 4. ICRISAT-4183; 5. ICRISAT-7722; 6. ICRISAT-7306; 7. BGD-70; 8. ICCV-5; 9. ICRISAT-3673; 10.F5-109; 11. F5-122; 12. F5-132; 13.F5-168; 14. ICRISAT-3668; 15. MPJK-4; 16. F5-119; 17. F5-164; 18. F5-170; 19. Pusa-1053; 20. Avarodhi.

largest cluster III consisting of fourteen genotypes and further sub-divided into four sub-clusters viz., IIIa, IIIb, IIIc and IIId. Cluster IIIa contains 8 genotype BGD-70; ICCV-5; F5-132; MPJK-4; F5-119; F5-164; F5-170; Pusa-1053 and rest three sub-clusters consisted of 2 genotypes each, cluster IIIb have F5- 109, and Avarodhi. The Avarodhi line reported to have resistance to fusarium wilt (Rizvi et al., 2014). Cluster IIIc consists of genotypes ICRISAT-3673; F5-122 and Cluster IIId consists of genotypes F5-168; ICRISAT3668 .

The similarity coefficient of cluster I have 0.694 which have only two genotypes F5-55and F5-936. In cluster II the maximum similarity coefficient was found in genotypes ICRISAT -4183 and ICRISAT-7722, which was 0.972 , and minimum similarity was in ICRISAT7722 and ICRISAT- 7306 was 0.833 . In cluster IIIa the maximum similarity was found in genotype BGD-70 and ICCV-5 and F5-164 and Pusa-1053 (0.972) and minimum similarity was found in genotypes ICCV-5 and F5-132 (0.861).Cluster IIIb has similarity (0.833) among genotypes F5-109 and Avarodhi. Cluster IIIc has genotypes ICRISAT-3673 and F5-122 of similarity (0.861) and the last cluster IIId has similarity upto (0.916) in genotypes F5-168 and ICRISAT-3668. In this way the cluster II shows similarity between ICRISAT varieties and cluster I show similarity between F5 varieties. The molecular dendrogram showed that ICRISAT -4183, BGD-70, F5-109, F5-164 and Pusa1053 were very close with similarity index (0.972) followed by F5-170 and F5-164 (0.944). The similar studies reported by Bouhadida et al. (2015)used STMS markers for assessing diversity among 38 accessions grouped in two major clusters according to their genetic similarity with a genetic similarity (GS) of 0.17 .

A total of 58 alleles were generated from the amplification of the 8 microsatellite sites studied with an average value of 7.25 alleles per locus, which explain a high level of polymorphism within the cultivars stud- 
ied. All the cultivars studied showed a unique genetic profile, each one using the genotypic combination of all loci studied.

Molecular markers have been widely utilized in breeding programme for estimation of genetic relationship between individuals, identification of crop cultivars, construction of linkage maps, mapping of genes for agronomical characters and disease resistance. Among the various DNA based markers, the microsatellite or STMS markers have become highly popular and the marker system of choice in diverse crop plants owing to their abundance in the genome, robustness, reproducibility, hyper variability and co- dominance (Powell et al., 1996a, 1996b). Application of STMS markers in genetic analysis of chickpea reported in the previous studies (Huttel et al., 1999; Winter et al., 1999; Choumane et al., 2000; Flandez-Galvez, 2003) since then the power and potential of SSR markers for a wide range of applications in genetics and breeding of chickpea has been well demonstrated by several researchers but still substantial numbers of chickpea accessions. The data of microsatellite and number of loci have potential to provide unique allelic profiles for DNA fingerprints for establishing genotypes identity. The utility of PCR-based markers such as STMSs for measuring diversity and in chickpea breeding programs is more than other markers, so these markers are become markers of choice and used routinely for marker assisted selection the close linkage of genes for resistance to fusarium wilt, several STMS markers are of great importance as it allows the use of at least one of the highly polymorphic markers for analysis of the segregation of wilt resistance gene in a wide range of germplasm.

\section{Conclusion}

The study revealed that in case of chickpea, $C$. arietinum, the value of Polymorphic information content ranged from 0 to 0.965 with an average of 0.373 specified the considerable efficiency of markers. All primer showed higher polymorphism among the genotypes except two primers namely, TAA59 and GA105 which were monomorphic in nature. The study has provided an insight of the inter-relationship among the genotypes and highlights the genetic distance by STMS markers to efficiently unearth the genetic interrelationship among the genotypes.. The study provides the basis for future chickpea crop variety identification, conservation, and management.

\section{ACKNOWLEDGEMENTS}

The authors are thankful to the Directors of the research institutes namely; IIPR, Kanpur, IARI, New Delhi and ICRISAT, Hyderabad for providing the genotypes for this study.

\section{REFERENCES}

Agarwal, G. Jhanwar, S. Priya, P. Singh, V.K. Saxena, M.S.
Parida, S.K. Garg, R. Tyagi, A.K. and Jain, M. (2012). Comparative analysis of kabuli chickpea transcriptome with desi and wild chickpea provides a rich resource for development of functional marker. PLoS One. 7 (12): 52443.

Bharadwaj, C. Chauhan, S.K. Rajguru, G. Srivastava, R. Satyavathi, C.T. Yadav, S. Rizvi, A.H. Kumar, J. and Solanki, R.K. (2010). Diversity analysis of chickpea (Cicer arietinum L.) cultivars using STMS markers. Indian J. Agri. Sci. 80: 947-951.

Bouhadida, M. Benjannet, R. Jendoubi, W. and Kharrat, M. (2015). Analysis of genetic diversity of chickpea cultivars using STMS markers. IOSR Journal of Applied Chemistry. 8(2):70-74.

Choumane, W. Winter, P. Weigand, F. and Kahl, G. (2000). Conservation and variability of sequence-tagged microsatellite sites (STMSs) from chickpea (Cicer arietinum L.) within the genus Cicer. Theor. Appl. Genet. 101(1-2):269-278.

Collard, B.C.Y. Jahufer, M.Z.Z. Brouwer, J.B. Pang, E.C.K. (2005). An Introduction to markers, quantitative trait loci (QTL), mapping and marker assisted selection for crop improvement: the basic concepts. Euphytica. 142:169-196.

Doddamani, D. Katta, M.A.V.S.K. Khan, A.W. Agarwal, G. Shah, T.M. and Varshney, R.K. (2014). CicArMiSatDB: the chickpea microsatellite database, $B M C$ Genomics, 15: 212.

Doyle, J.J. and Doyle, J.L. (1987). A rapid DNA isolation procedure from small quantities of fresh leaf tissues. Phytochem. Bull., 19:11-15.

Flandez-Galvez, H. Ford, R. Pang, E.C.K. and Taylor, P.W. J. (2003). An intraspecific linkage map of the chickpea (Cicer arietinum L.) genome based on sequence tagged microsatellite site and resistance gene analog markers. Theor. Appl. Genet., 110(7):447-1456.

Gaur, P.M. Jukanti, A.K. and Varshney, R.K. (2012). Impact of genomic technologies on chickpea breeding strategies. Agronomy, 2:199-221.

Gawel, N.J. and Jarret, R.L. (1991). A modified CTAB DNA extraction procedure for Musa and Ipomoea plant. Mol. Biol. Rep., 9:262-266.

Huttel, B. Winter, P. Weising, K. Choumane, W. Weigand, F. and Kahl, G. (1999). Sequence tagged microsatellites site markers for chickpea (Cicer arietinum L.). Genome, 42:210-217.

Jaccard, P. (1908). Nouvelles recherches surla distribution florale. Bull. Soc. Sci. Nat., 44:223-270

Jukanti, A.K. Gaur, P.M. Gowda, C.L.L. and Chibbar, R.N. (2012). Nutritional quality and health benefits of chickpea (Cicer arientium L.): A review, Br. J. Nutr. 108 (Suppl. 1):S11-S16.

Kupitcha, F.K. (1977). The delimitation of the tribe Viceae (Leguminoeceae) and the relationship of Cicer. Botanical journal of Linnean Society, 74: 12-13.

Poncet, V., Rondeau, M., Tranchant, C., Cayrel, A., Hamon, S., Kochko, A.D. and Hamon, P. 2006. SSR mining in coffee tree databases: potential use of EST-SSRs as marker for the Coffea genus, Theor. Appl. Genet., 276: 436-449.

Powell, W. Marchy, G.C. and Provan, J. (1996a). Polymorphism revealed by simple sequence repeats. Trends Plant Sci., 1:215-222.

Powell, W. Morgante, M. Andes, C. Hangley, M. Vogel, J. Tingey, S. and Raflski, A. (1996b). The comparison of 
RFLP, RAPD, AFLP, and SSR microsatellites markers for germplasm analysis. Mol. Breed., 2: 225-238.

Rizvi, H. Kalyana Babu, B. and Agrawal, P.K. (2014). Molecular analysis of kabuli and desi type of Indian chickpea (Cicer arietinum L.) cultivars using STMS markers. J. Plant Biochem. Biotech., 23(1):52-60

Rohlf, F.J. (1989). NTSYS-pc (Numerical Taxonomy and Multivariate Analysis System).Ver.1.70. Exeter, Setauket, New York.

Senior, M.L. Murphi, J.P. Goodman, M.M. and Stuber, C.W. (1998). Utility of SSRs for determining genetic similarities and relationship in Maize using an Agarose gel system. Crop Sci., 38:1088-1098.

Sethy, N.K. Choudhary, S. Shokeen, B. and Bhatia, S. (2005). Identification of microsatellite markers from Cicer reticulatum: molecular variation and phylogenetic analysis. Theor. Appl. Genet., 112(2):347-357.

Singh, R., Vibha, S. and Randhawa, G.J. (2008). Molecular analysis of chickpea (Cicer arietinum L.) cultivars using AFLP and STMS markers. J. Plant Biochem. Biotech. 17:167-171.

Sneath, P.H.A. and Sokal, R.R. (1973). Numerical Taxonomy WH Truman \& Co San Francisco.

Varshney, R.K. and Tuberosa, R. (2013). Genomics applications in crop breeding for biotic stress tolerance, an introduction. In: Varshney, R.K., Tuberosa, R. (eds.) Translational Genomics for Crop Breeding: Biotic Stress, vol I. Willey Blackwell, Hoboken, 1-9.

Weir, B.S. and Buckleton, J.S. (1996). Statistical issues in DNA profiling. Advances in Haemogenetics, 6:457-464.

Winter, P. Pfaff, T. Udupa, S.M. Huttel, B. Sharma, P.C. Sahi, S. Arreguin-Espinoza, R. Weigand. F. Muehlbauer, F.J. and Kahl, G. (1999). Characterization and mapping of sequence-tagged microsatellite sites in the chickpea (Cicer arietinum L.) genome. Mol. Gen. Genet. 262 (1):90-101. 